\title{
Weathering stoichiometry: A critical factor to estimate soil acidification rate $^{\$}$
}

\author{
JIN-LING YANG ${ }^{1,2}$, GAN-LIN ZHANG ${ }^{1,2 *}$
}

${ }^{1}$ State Key Laboratory of Soil and Sustainable Agriculture, Institute of Soil Science, Chinese Academy of Sciences, Nanjing 210008, China

${ }^{2}$ University of Chinese Academy of Sciences, Beijing 100049, China

* correspondence: glzhang@issas.ac.cn

Soil acidification is widespread in the world. However, how to accurately estimate current soil acidification rate is still a hard scientific problem because of soil acid-buffering mechanism. To explore a new method to accurately estimate soil acidification, a forested watershed with acid deposition, located in subtropical area, China, was selected. The input and output of proton $\left(\mathrm{H}^{+}\right)$and related elements from the watershed had been monitored for three years. The soils sampled from the watershed were eluted exchangeable base cations $(\mathrm{K}, \mathrm{Na}, \mathrm{Ca}, \mathrm{Mg})$, then leached by simulated acid rain to obtain the weathering stoichiometric relation of base cations to $\mathrm{Si}(\mathrm{BC}: \mathrm{Si})$.

The net input of $\mathrm{H}^{+}$from both wet and dry deposition was about $1395 \mathrm{~mol} \mathrm{ha}^{-1} \mathrm{yr}^{-1}$ in the watershed, including directly from acid rain, transformations from nitrogen and sulfur. However, the runoff water was neutral, meaning that soil consumed all $\mathrm{H}^{+}$. The specific adsorptions of extraneous $\mathrm{SO}_{4}{ }^{2-}$ in soil produced $\mathrm{OH}^{-}$and consumed $\mathrm{H}^{+}$about $93 \mathrm{~mol}$ $\mathrm{ha}^{-1} \mathrm{yr}^{-1}$. The remained $\mathrm{H}^{+}$in soil was consumed by cation exchange and mineral weathering. The leached experiment of acid rain showed that $\mathrm{BC}: \mathrm{Si}$ was 1:1 during the soil mineral weathering. Based on $\mathrm{BC}: \mathrm{Si}$ and the net output of base cation and $\mathrm{Si}$ in the watershed, we found that weathering consumed $1068 \mathrm{~mol} \mathrm{ha}^{-1} \mathrm{yr}^{-1} \mathrm{H}^{+}$, about two times more than the estimation in previous study based on plagioclase weathering[1]. The $\mathrm{H}^{+}$consumed by cation exchange only took up one fifth of total $\mathrm{H}^{+}$input. The soil acidification rate was $234 \mathrm{~mol} \mathrm{ha}^{-1} \mathrm{yr}^{-1}$.

The method of estimating soil acidification rate based on weathering stoichiometric relation of BC:Si is very effective. This study illustrates that previous methods only using input $\mathrm{H}^{+}$and leaching of base cations highly overestimated soil acidification rate.

[1] Yang et al. (2013) Chem.Geol. 337-338, 30-37.

$\$$ Research was financially supported by the National Natural Science Foundation of China (Nos. 41877010; 41571130051). 